\title{
FAKTOR-FAKTOR YANG MEMPENGARUHI FINANCIAL BEHAVIOR
}

\author{
Paula Elicia \\ Program Studi Magister Manajemen Universitas Tarumanagara \\ paulaelicia@gmail.com \\ Indra Widjaja \\ Program Studi Magister Manajemen Universitas Tarumanagara
}

Masuk : 01-12-2020, revisi : 22-12-2020, diterima untuk diterbitkan : 22-12-2020

\begin{abstract}
There are many factors that can affect individual life sustainability, both in short term and long term. One of the factors is decision to manage finance. The ability to manage the finance is not only to get sufficient income, but also the ability to manage finances more wisely and appropriately. The purpose of this research is to analyze the impact of Parental Influence, Financial Knowledge, Financial Attitude and Income on Financial Behavior. The population of this research is the clients of Bank BCA in Jakarta; who have earned income and have graduated with at least an S1 degree. The total sample is 298 respondents, were selected using convenience sampling method and data processing techniques used are taken from Structural Equation Modeling (SEM), that is supported by SmartPLS.3.3.2 program. The result of this study reveals that Parental Influence and Income has no significance influence on Financial Behavior; while Financial Knowledge and Financial Attitude do have a significance influence on Financial Behavior.
\end{abstract}

Keywords: Parental Influence, Financial Knowledge, Financial Attitude, Income, Financial Behavior

Abstrak: Terdapat banyak faktor yang dapat mempengaruhi kelangsungan hidup individu, baik dalam jangka pendek maupun jangka panjang. Salah satu faktor diantaranya adalah keputusan dalam mengatur keuangan. Kemampuan dalam mengatur keuangan bukan hanya pada kemampuan untuk mendapatkan pendapatan yang cukup, melainkan juga kemampuan untuk mengelola keuangan secara bijak dan tepat. Tujuan penelitian ini adalah untuk menganalisa pengaruh Parental Influence, Financial Knowledge, Financial Attitude dan Income terhadap Financial Behavior. Populasi penelitian ini adalah nasabah dari Bank BCA di Jakarta yang sudah mempunyai penghasilan dan mempunyai tingkat pendidikan minimal S1. Sampel yang mencapai jumlah total 298 responden dipilih menggunakan metode convenience sampling. Teknik pengolahan data menggunakan Structural Equation Modeling (SEM) yang didukung oleh program SmartPLS.3.3.2. Hasil penelitian ini mengungkapkan bahwa Parental Influence dan Income tidak berpengaruh terhadap Financial Behavior; sedangkan Financial Knowledge dan Financial Attitude berpengaruh terhadap Financial Behavior.

Kata kunci: Parental Influence, Financial Knowledge, Financial Attitude, Financial Behavior

\section{PENDAHULUAN}

Berdasarkan survey yang dilakukan oleh Otoritas Jasa Keuangan (2017), pada tahun 2016 sebanyak 96,81\% sikap keuangan masyarakat terkait tujuan keuangan masih didominasi dengan tujuan jangka pendek seperti 49,11\% untuk memenuhi kehidupan sehari- hari, 17,68\% untuk bertahan hidup dan $8 \%$ untuk biaya pendidikan anak. Hal ini berarti bahwa, masyarakat Indonesia saat ini masih cenderung menggunakan keuangan mereka unx tuk jangka pendek dan belum memikirkan dan menerapkan perencanaan atau pengelolaan keuangan untuk jangka panjang. Perilaku seperti ini dapat menyebabkan kegagalan keuangan individu di masa yang akan datang akibat kesalahan dalam mengelola keuangan mereka. Berdasarkan hasil survey 
tersebut, maka dapat disimpulkan bahwa masyarakat saat ini masih membutuhkan pendidikan dan pengetahuan mengenai perilaku keuangan dalam kehidupan sehari-hari mereka.

Financial Behavior (perilaku keuangan) merupakan salah satu konsep yang sangat penting dalam ilmu keuangan. Beberapa indikator yang dapat dilakukan dalam meningkatkan pengelolaan dan pengendalian keuangan individu yang baik yaitu seperti menilai pembelian berdasarkan kebutuhan, mengatur arus kas masuk dan keluar, melakukan investasi dan tabungan untuk jangka panjang, serta mengatur anggaran. Pengaruh dari orang tua merupakan salah satu sumber pengaruh terbesar pada pengetahuan dan sikap anak terhadap keuangan (Financial Knowledge dan Financial Attitude). Variabel lain yang dapat mempengaruhi Financial Behavior adalah Financial Knowledge (Pengetahuan Keuangan). Financial Knowledge adalah pengetahuan seseorang atas berbagai macam hal mengenai keuangan (Kholilah \& Iramani, 2013). Individu yang memiliki pengetahuan keuangan yang baik, maka akan lebih bijak dalam melakukan keputusan keuangan. Financial Attitude dapat dijadikan sebagai suatu aplikasi dalam mengambil keputusan keuangan dengan tepat. Sikap keuangan merupakan penerapan yang dilakukan atau ditunjukkan oleh individu dalam pengambilan keputusan keuangan. Salah satu variabel penentu perilaku keuangan adalah pendapatan (Income). Saat ini, banyak individu yang belum menggunakan pendapatannya dengan baik seperti menabung, melakukan investasi dan melakukan pengeluaran keuangan sesuai dengan kebutuhan.

\section{Tujuan Penelitian}

Untuk menganalisis pengaruh Parental Influence, Financial Knowledge, Financial Attitude dan Income terhadap Financial Behavior pada nasabah Bank BCA di Jakarta.

\section{TINJAUAN PUSTAKA}

\section{Parental Influence dan Financial Behavior}

Menurut penelitian Jorgensen dan Savla (2010), diperoleh kesimpulan bahwa terdapat pengaruh Parental Influence terhadap Financial Behavior. Jorgensen dan Savla (2010, h. 474) menyatakan bahwa, "The perceived Parental Influence construct consisted of two main ideas: (a) the amount of financial learning that took place and $(b)$ the frequency of financial learning." Parental Influence menjadi peran yang penting dalam pengembangan kemampuan individu. Orang tua menjadi salah satu media utama dalam pembentukan cara pandang seorang individu mengenai keuangan.

\section{Financial Knowledge dan Financial Behavior}

Menurut penelitian Perry dan Morris (2005), diperoleh kesimpulan bahwa terdapat pengaruh Financial Knowledge terhadap Financial Behavior. Financial Knowledge merupakan pemahaman individu mengenai istilah-istilah dan konsep-konsep finansial yang dibutuhkan dan berfungsi untuk kehidupan sehari-hari dalam pengambilan keputusan dan pengelolaan keuangan (Bowen, 2002).

\section{Financial Attitude dan Financial Behavior}

Menurut penelitian Jorgensen dan Savla (2010), diperoleh kesimpulan bahwa terdapat pengaruh Financial Attitude terhadap Financial Behavior. Financial Attitude dapat didefinisikan sebagai sikap atau penerapan individu dalam pengambilan keputusan keuangan dan dalam mengelola keuangan mereka. Menurut Parrota dan Johnson (1998, h. 60), "Financial Attitudes can be considered the psychological tendency expressed when evaluating recommended financial management practices with some degree of agreement or disagreement." Financial Attitude merupakan kecenderungan psikologis individu dalam menerapkan praktek pengelolaan keuangan. Sikap yang ada akan menghasilkan cara yang berbeda, tergantung pada lingkungan individu yang membentuknya (Widjaja, Arifin and Setini, 2020). 


\section{Income dan Financial Behavior}

Menurut penelitian Ida \& Dwinta (2010) dan Arifin (2017) diperoleh kesimpulan bahwa tidak terdapat pengaruh Income terhadap Financial Behavior. Tetapi hasil penelitian Perry \& Morris (2005) menyatakan bahwa income memiliki pengaruh positif terhadap Financial Behavior. Orang-orang yang memiliki tingkat pendapatan yang tinggi tidak selalu mampu mengelola pengeluarannya dengan cara yang baik dan tepat, yang disebabkan oleh sikap yang tidak bertanggung jawab dalam perilaku keuangan dan kencenderungan untuk berpikir jangka pendek (Arifin, 2017).

Gambar 1

\section{Hubungan antar Variabel}

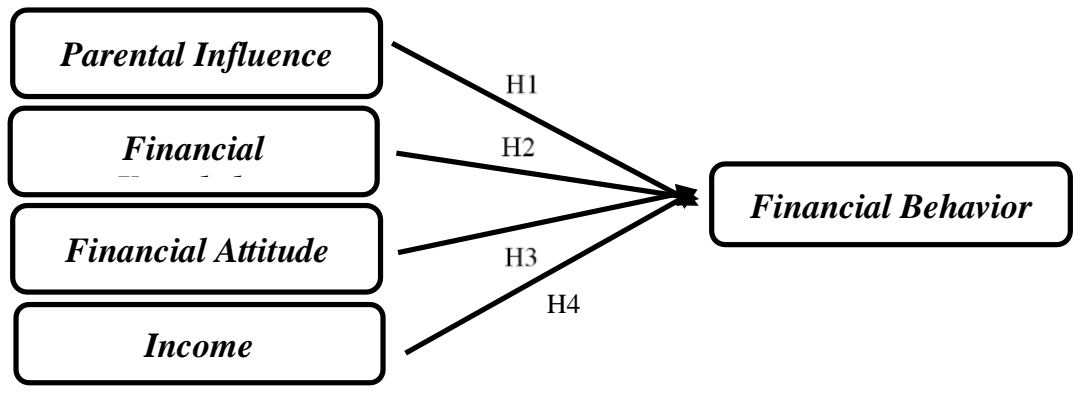

$\mathrm{H}_{1}$ : Terdapat pengaruh Parental Influence terhadap Financial Behavior.

$\mathrm{H}_{2}$ : Terdapat pengaruh Financial Knowledge terhadap Financial Behavior.

$\mathrm{H}_{3}$ : Terdapat pengaruh Financial Attitude terhadap Financial Behavior.

$\mathrm{H}_{4}$ : Terdapat pengaruh Income terhadap Financial Behavior.

\section{METODOLOGI PENELITIAN}

Penelitian ini menggunakan penelitian deskriptif kuantitatif. Teknik pemilihan sampel dalam penelitian ini adalah non-probability sampling dengan menggunakan convenience sampling. Pengumpulan data yang dilakukan pada penelitian ini menggunakan kuesioner dan diuji dengan menggunakan metode partial least square-structural equation modeling (PLSSEM) dengan menggunakan software SmartPLS 3.3.2. Jumlah responden yang digunakan dalam penelitian ini adalah 298 responden yang dikelompokkan berdasarkan jenis kelamin, usia, pendidikan terakhir, pekerjaan, domisili.

\section{Tabel 1}

Variabel Data Pengukuran

\begin{tabular}{|l|c|c|}
\hline \multicolumn{1}{|c|}{ Variabel } & Jumlah Indikator & Sumber \\
\hline Variabel Bebas & 3 & Cho, Gutter, Kim dan Mauldin (2012) \\
1. Parental Influence & 5 & Perry dan Morris (2005) \\
2. Financial Knowledge & 8 & Rajna dan Anthony (2011) \\
3. Financial Attitude & 1 & Perry \& Morris (2005) \\
4. Income & 6 & Dew dan Xiao (2011) \\
\hline Variabel Terikat & & \\
Financial Behavior & & \\
\hline
\end{tabular}

\section{Hasil Uji Statistik}

\section{Uji Validitas}

\section{Convergent Validity}

Tabel 2

Hasil Analisis Average Variance Extracted (AVE)

\begin{tabular}{|c|c|}
\hline Variabel & Average Variance Extracted (AVE) \\
\hline Financial Attitude & 0,554 \\
\hline Financial Behavior & 0,552 \\
\hline Income & 0,574 \\
\hline Financial Knowledge & 1,000 \\
\hline Parental Influence & 0,601 \\
\hline
\end{tabular}




\section{Gambar 2}

\section{Hasil Analisis Validitas Konvergen}

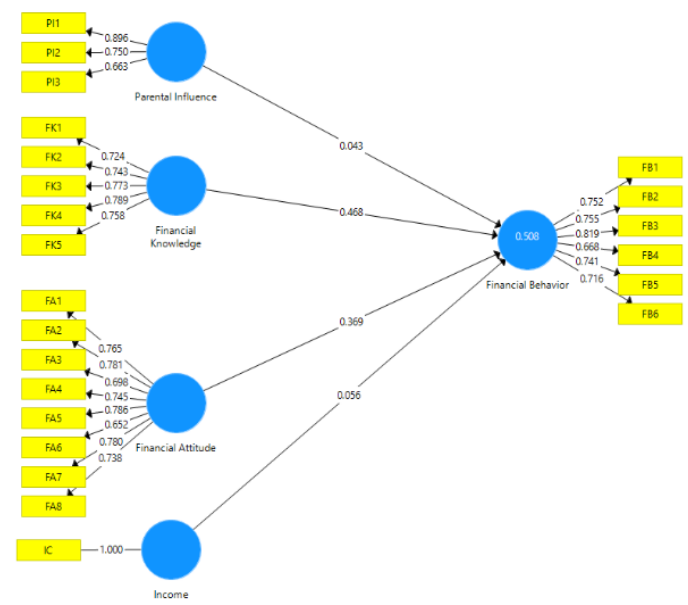

Tabel 2 dan Gambar 2 menunjukkan hasil pengujian validitas konvergen yang menjelaskan bahwa semua indikator pada penelitian ini memiliki nilai AVE dan loading factor $>0,5$ (Abdillah dan Jogiyanto, 2015) yang berarti bahwa indikator-indikator yang mengukur variabel penelitian telah memenuhi validitas konvergen.

\section{Discriminant Validity}

Untuk menguji validitas diskriminan digunakan nilai cross loading dan Fornell-Larcker. Berdasarkan hasil yang penelitian ini, diketahui masing-masing indikator pada memiliki nilai cross loading terbesar pada variabel yang dibentuknya dibandingkan pada variabel lainnya sehingga indikator-indikator yang digunakan dalam penelitian telah memenuhi validitas diskriminan (Fornell \& Lacker, 1981).

\section{Tabel 5}

Hasil Fornell-Larcker

\begin{tabular}{|c|c|c|c|c|c|}
\hline Variabel & $\begin{array}{c}\text { Financial } \\
\text { Attitude }\end{array}$ & $\begin{array}{c}\text { Financial } \\
\text { Behavior }\end{array}$ & $\begin{array}{c}\text { Financial } \\
\text { Knowledge }\end{array}$ & Income & $\begin{array}{c}\text { Parental } \\
\text { Influence }\end{array}$ \\
\hline Financial Attitude & $\mathbf{0 . 7 4 4}$ & & & & \\
\hline $\begin{array}{c}\text { Financial } \\
\text { Behavior }\end{array}$ & 0.572 & $\mathbf{0 . 7 4 3}$ & & & \\
\hline $\begin{array}{c}\text { Financial } \\
\text { Knowledge }\end{array}$ & 0.445 & 0.629 & $\mathbf{0 . 7 5 8}$ & & \\
\hline Income & -0.114 & 0.004 & -0.025 & $\mathbf{1 . 0 0 0}$ & \\
\hline Parental Influence & 0.042 & 0.047 & -0.028 & 0.035 & $\mathbf{0 . 7 7 5}$ \\
\hline
\end{tabular}

\section{Uji Reliabilitas}

Untuk menguji reliabilitas konstruk (variabel) digunakan nilai cronbach's alpha dan nilai composite reliability. Rule of thumb nilai Cronbach's Alpha atau Composite Reliability harus lebih besar dari 0,7 meskipun nilai 0,6 masih dapat diterima (Abdillah \& Jogiyanto, 2015). Maka dapat disimpulkan bahwa masing-masing variabel dapat dikatakan reliabel apabila memiliki nilai Cronbach's Alpha dan Composite Reliability $\geq 0,6$.

Dalam penelitian ini, seluruh indikator memiliki nilai cronbach's alpha $>0,6$ dan nilai composite reliability > 0,6 yang berarti bahwa masing-masing variabel penelitian reliabel karena telah memenuhi reliabilitas konstruk.

Tabel 6

Hasil Analisis Reliabilitas

\begin{tabular}{|c|c|c|}
\hline Variabel & Cronbach's Alpha & Composite Reliability \\
\hline Financial Attitude & 0.885 & 0.908 \\
\hline Financial Behavior & 0.837 & 0.881 \\
\hline Income & 0.815 & 0.871 \\
\hline Financial Knowledge & 1.000 & 1.000 \\
\hline Parental Influence & 0.683 & 0.817 \\
\hline
\end{tabular}




\section{Hasil Pengujian Hipotesis}

Tabel 7

Hasil Pengujian Hipotesis

\begin{tabular}{|c|c|c|c|}
\hline Variabel & Path Coefficients & t-statistics & p-values \\
\hline Financial Attitude - Financial Behavior & 0.369 & 6.554 & 0.000 \\
\hline Financial Knowledge - Financial Behavior & 0.468 & 7.773 & 0.000 \\
\hline Income - Financial Behavior & 0.056 & 1.365 & 0.173 \\
\hline Parental Influence - Financial Behavior & 0.043 & 0.807 & 0.420 \\
\hline
\end{tabular}

Berdasarkan hasil yang terdapat pada Tabel 7, variabel Parental Influence dan Income tidak berpengaruh terhadap Financial Behavior. Variabel Financial Knowledge dan Financial Attitude berpengaruh terhadap Financial Behavior.

\section{HASIL DAN KESIMPULAN}

$\mathrm{H}_{1}$ : Parental Influence tidak berpengaruh terhadap Financial Behavior.

$\mathrm{H}_{2}$ : Financial Knowledge berpengaruh terhadap Financial Behavior.

$\mathrm{H}_{3}$ : Financial Attitude berpengaruh terhadap Financial Behavior.

$\mathrm{H}_{4}$ : Income tidak berpengaruh terhadap Financial Behavior.

\section{PENUTUP}

Berdasarkan hasil dari penelitian ini, maka beberapa saran yang sekiranya dapat diberikan dan bermanfaat bagi beberapa pihak, antara lain sebagai berikut:

1. Menambah jumlah responden penelitian, sehingga hasil yang diperoleh dapat lebih akurat dan mampu memperkuat hasil penelitian.

2. Menambah variabel-variabel lainnya yang diduga dapat mempengaruhi Financial Behavior seperti Financial Satisfaction, Demographic Variables, Financial Confidence, Locus of Control, Income dan lain sebagainya.

3. Bagi perusahaan perbankan (khususnya bagi Bank BCA), disarankan untuk memberikan edukasi keuangan kepada masyarakat (khususnya nasabah dari Bank BCA) mengenai cara pengelolaan keuangan yang baik agar masyarakat mempunyai pengetahuan keuangan dan perilaku keuangan yang baik.

4. Bagi perusahaan perbankan (khususnya bagi Bank BCA), agar nasabah mempunyai sikap keuangan yang baik maka perusahaan perbankan perlu memberikan sosialisasi kepada masyarakat bahwa disiplin dalam menabung merupakan hal yang penting sehingga diharapkan masyarakat (khususnya nasabah dari Bank BCA) akan memiliki perilaku keuangan yang baik.

\section{DAFTAR PUSTAKA}

Abdillah, W., \& Jogiyanto, H. M. (2015). Partial Least Square, Alternative Structural

Amanah, E., Rahadian, D., \& Iradianty, A. (2016). Pengaruh Financial Knowledge, Financial Attitude Dan External Locus Of Control Terhadap Personal Financial Management Behavior Pada Mahasiswa S1 Universitas Telkom. E-Proceeding Of Management, 3, 1228-1235.

Arifin, A. Z. (2017). The Influence Of Financial Knowledge, Control And Income On Individual Financial Behavior. European Research Studies Journal, Xx(3a), 635-648.

Bowen, C. F. (2002). Financial Knowledge of Teens and Their Parents. Financial Counseling and Planning, 13(2), 93-102.

Cho, S. H., Gutter, M., Kim, J., \& Mauldin, T. (2012). The Effect Of Socialization And Information Source On Financial Management Behaviors Among Low- And ModerateIncome Adults. Family \& Consumer Sciences Research Journal, 40(4), 417-430.

Dew, J., \& Xiao, J. J. (2011). The Financial Management Behavior Scale: Development And Validation.Journal Of Financial Counseling And Planning, 22(1), 43-59. 
Fornell, C., \& Larcker, D. F. (1981). Structural equation models with unobservable variables and measurement error: Algebra and statistics. Journal of marketing research, 382-388.

Ida, \& Dwinta, C. Y. (2010). Pengaruh Locus Of Control, Finacial Knowledge, Income Terhadap Financial Management Behavior. Jurnal Bisnis Dan Akuntansi, 12(3), 131144.

Jorgensen, B. L., \& Savla, J. (2010). Financial Literacy Of Young Adults: The Importance Of Parental Socialization. Family Relations, 59, 465-478.

Keuangan, O. J. (2017). Survei Nasional Literasi dan Inklusi Keuangan 2016. Retrieved September 27, 2018, from http://www.ojk.go.id.

Kholilah, N. A., \& Iramani, R. (2013). Studi Financial Management Behavior Pada Masyarakat Surabaya. Journal Of Business And Banking, 3(1), 69-80.

Parrotta, J. L., \& Johnson, P. J. (1998). The Impact Of Financial Attitudes And Knowledge On Financial Management And Satisfaction Of Recently Married Individuals. Journal of Financial Counseling And Planning, 9(2), 59-75.

Perry, V. G., \& Morris, M. D. (2005). Who Is In Control? The Role Of Self-Perception, Knowledge, And Income In Explaining Consumer Financial Behavior. The Journal of Consumer Affairs, 39(2), 299-313.

Rajna, A., \& Anthony, P. (2011). Knowledge, Attitude, Practice and Satisfaction on Personal Financial Management Among The Medical Practitioners In The Public And Private Medical Services In Malaysia (Doctoral Dissertation, Phd Thesis, Universiti Kebangsaan Malaysia).

Widjaja, I., Arifin, S., \& Setini, M. (2020). The effects of financial literacy and subjective norms on saving behavior. Management Science Letters, 10(15), 3635-3642. 